\title{
A SURGICAL METHOD OF DEALING WITH KERATOCONUS
}

\author{
BY \\ George Young \\ COLCHESTER
}

Miss D. G., aged $1 \tau$ years, first consulted me about her eyes at the Essex County Hospital on November 2, 1921. Both corneae were intensely conical and thus very much thinned at the apices, the left one being far the more advanced and already showing signs of opacity from exposure at the apex. The right cornea was still clear.

R.V.: $6 / 36$, c. $-2.0 \mathrm{D}$ sph.+3.50D cyl. $155^{\circ} ; 6 / 18$ pt., $6 / 12$ pt., and shapes $6 / 9$.

L.V. : fingers at 2 metres; empirical attempts here were of little avail, though the patient seemed to see a little better with $-2.0 \mathrm{D}$ sph. - 3.0D cyl. $125^{\circ}$. But that was purely subjective.

The patient was an extremely delicate girl, pale and thin, sallow skin, acne, brown hair and iris, suffering from bronchitis and asthma and in the course of the following treatment had bronchopneumonia at Christmas 1922. From the first date till this attack she was treated steadily with 1 per cent. pilocarpin, and bandage at night. During her attack of pneumonia she interrupted her treatment till January 3,1923 , when she reappeared, with the whole central portion of the left cornea bulging between the eyelids, and in fact showing a staphyloma of the cornea the size of a large pea. Bursting was imminent, and I devised this operation with the view of attempting to save the eye, and carried it out on March 19, 1923. Of course there was no more form vision, and only movements could be seen.

The cornea was transfixed by four needles, entering the anterior chamber outside the base of the staphyloma, and issuing at a point symmetrically opposite, as shown in Fig. 1 and Fig. 2. For the two horizontal transfixions two ordinary fine sewing needles were used. For the two vertical ones curved needles had to be used, to escape the prominence of the supraorbital ridge. Two silk sutures were used. "Each pair of needles were threaded with the two ends of one of these. Then each needle was drawn through and both sutures tied firmly, constricting the whole staphyloma at its base, like a purse string draws the mouth of a purse together and closes it; then the whole staphyloma was sliced off by means of a keratome and to and fro sawing movements of one of its sharp edges. Atropin and a light bandage were applied. The sutures were easily pulled out on the fifth day. Patient was discharged with atropin drops in a week. There was no reaction, and to my 
surprise, the after treatment had been painless. I expected it to be very painful. Also the puckering of the cornea disappeared and smoothed down into a regular spherical surface in so brief a time, that inside of a month (I saw her for the first time after operation on April 8), no one would have suspected that abscission had been performed at all, there being only a stellate leucoma at the centre of the cornea, The peripheral portions of the cornea were clear. Two months later, June 18, I performed an optical iridectomy, down and in, as atropin dilatation of the pupil did not produce any dilatation downwards, the iris evidently having become adherent to the leucoma all along the lower portion. Upwards the pupil dilated in a sinuous bulge, only with no visual benefit, as it was covered by the eyelid, and for some reason, even

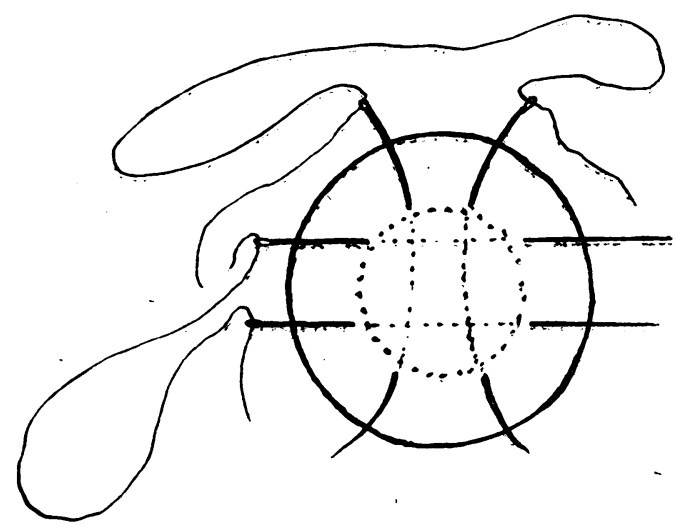

Fig. 1.

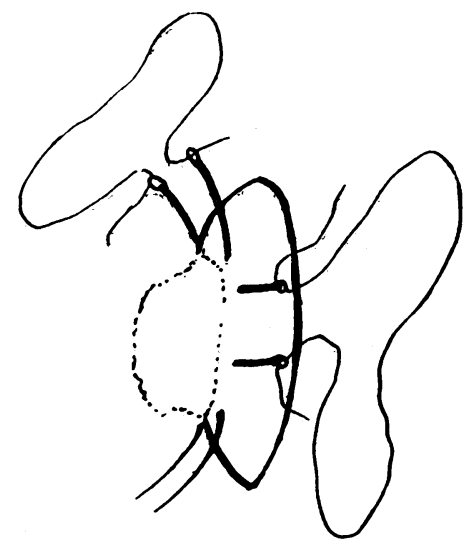

Fig. 2. Profile.

the raising of the eyelid produced no form vision. The result, however, of the optical iridectomy down and in was immediate. The vision, which was mere shadows before, was, immediately after the iridectomy, equal to correct counting of fingers, and two days after the operation, June 20 , the vision was fingers at 4 metres, and the eye was quiet. The patient was discharged and kept under atropin ter die, and on July 4 visual tests were made at the hospital. The first attempt at correction was : L.V.: 6/60, c. $-1.50 \mathrm{D}$ sph. $+2.0 \mathrm{D}$ cyl., axis $60^{\circ}: 6 / 36$.

This was a very rough test, and later the ophthalmometer showed a considerable astigmatism with the axis corresponding roughly to the direction of the coloboma, at about $45^{\circ}$, but not measurable in amount, though I endeavoured to take the measurement by fixing the eye so that the iridectomized portion of the cornea was opposite the telescope. But the visual result was remarkably good: L. V.: $6 / 60$, c. $+1.0 \mathrm{D}$ sph. $-3.0 \mathrm{D}$ cyl. $45^{\circ}: 6 / 24$. And with 
added plus lenses (eye being under atropin), J.2, fluently. This made her left eye equal, for distance, to her better eye, which is now getting worse owing to increased bulging, and will probably follow the course of the other one soon.

R.V.: 6/36, c. $-1.0 \mathrm{D}$ sph.+3.50D cyl. $155^{\circ}: 6 / 24$ and J.5. Furthermore, it may be noted that the intraocular tension was now normal on the side of the iridectomy, while the right eye was hard, and I submitted it again to pilocarpin and bandage at night. I sent her home for a fortnight to feed up, take malt and cod liver oil and fats, and to take plenty of rest and recuperate. On July 8 the final result was :

L.V.: 6/36, c. $-5.0 \mathrm{D}$ sph. +3.50D cyl. $160^{\circ}: 6 / 12$ full, and $-3.0 \mathrm{D}$ sph. and +3.50D cyl. J.2.

Soon I shall tattoo the stellate leucoma with an artificial pupil.

May 10, 1924. Since writing the above, some ten months ago, affairs have kept steady. There is no bulging of the left cornea or scar. I attempted tattooing at two sittings, and have considerably diminished the glare of the scar, but I refrain from risking the deep tattooing necessary for securing an imitation round black pupil, fearing to do harm. Glasses were prescribed and worn with comfort and great help, the vision being maintained as above. The right eye still holds its own with miotics and an occasional use of bandage at night. The patient's general condition has been built up successfully and I emphasize the importance of this in all cases where debility or other causes require it.

\section{AN OPERATION FOR CONGENITAL PTOSIS}

\section{BY}

\section{George Young}

COLCHESTER

ON July 17, 1923, Miss E. W., of Wivenhoe, consulted me about the condition of her right eye. Fig. 1 shows her appearance, due to the congenital absence of the levator palpebrae. The right face was distorted in the usual way by complete ptosis, absence of the palpebral fold, inability to raise the right eyelid, even with the frontalis muscle, which merely threw the forehead on the right side into multiple transverse folds, raising the right eyebrow threequarters of an inch above the left, and productive of a continuous "tic" - the constant impulse to lift the lid sufficiently to let the right eye take part in the act of vision. Altogether a most disfiguring state to behold, in an otherwise graceful and attractive young woman. I will dwell only on the functional disturbance 